\title{
Design of Self-sustaining Mariculture Farm on Offshore Rig
}

\author{
Sharul Sham Dol
}

\author{
Department of Mechanical Engineering, Abu Dhabi University, P.O. Box 59911, Abu Dhabi, UAE
}

Abstract: Oil and gas offshore platform is only allowed to be sited up to a certain number of years depending on the availability of oil production and environmental-related issues. Any offshore platform that is out of its main service will be decommissioned due to the government policy to restore the natural condition of ocean environment. This process is very costly and makes the platform owner to find alternatives. The ideas include of converting this platform into; prison, marine resort, artificial reefs, diving platform, oyster depuration and mariculture fish farm. Basically, all of the ideas will contribute in making profit besides reducing cost from the decommissioning process. Deep sea fish farming or mariculture is a prospective business for countries surrounded by the sea and it can provide half of all seafood consumed in the world. Since the farm will be located offshore in deep waters, it is required that the farm to be operated with minimal human interaction and will be able to internally generate required amount of energy to remain self-sustaining. The energy requirement for the activities on the platform can be generated from the available renewable energy source such as; wind, tidal or wave, vortex-induced ocean current and solar energy. The design of this offshore mariculture farm is integrated with these renewable energy systems. The study creates public awareness and knowledge on environmental educational issues associated with deep sea fish farming as well as offshore renewable energy application for marine life sustainability.

Keywords: decommissioned platform; environmental; offshore mariculture; renewable energy

\section{Introduction}

Abandoned or decommissioned offshore platform is a retired oil and gas extraction platform after their profitable life of oil and gas production. In most of the oil producer country, this decommissioned offshore platform is required to be removed from the location to restore the previous natural habitat and ecology of that particular area of ocean and for safety of the oceanic transportation (Figure 1). Removing the platform that located far away from shore and some of the structure cannot be disassembled made the whole removal procedure costly and might require billions of dollar (Kurian, 2009). This costly procedure finally made the generation of ideas purposely to reduce the removing cost by reusing the decommissioned platform for other purposes such as marine culture, hotel and diving resort, artificial reef and rig, marine research center and control center (O'Connor, 1999). From the ideas generated, these alternatives for decommissioned platform seem to be much better option than removing the whole platform in terms of economic, future marine habitat, future seafood consumption needs and local job opportunity. Some of the ideas have been successfully applied such as; hotel resort and as diving spot center. This work focuses on the potential of an offshore mariculture (deep sea fish farming) and the application of renewable energy on the platform to support the fish farming activities.

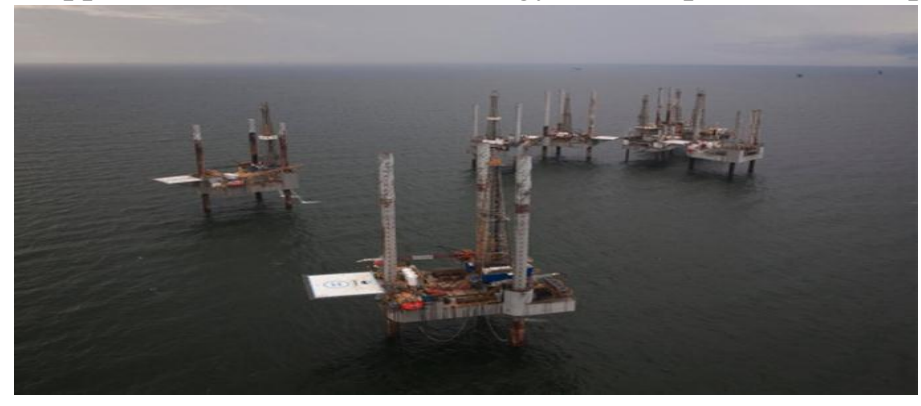

Figure 1: Oil platforms that provide habitat of the underwater creatures after being dried up in the Celebes Sea.

Since there are uncountable decommissioned platforms in the Gulf of Mexico and even all around the world, the offshore concept of mariculture might be successful and realistic. First, the seafood supply and demand is 
growing rapidly in almost all the developed nations and there is limited capacity from wild harvests that is approximately 100 million metric tons/ year. (Sarah, 2011) The increasing demand forces the other ways of fishery.

The idea of offshore fish farming is chosen mainly due to its potential revenue, minor addition structure needs, low energy requirement and the present structure of the platform that can be used to aid with the fish farming activities. Fish farming on offshore platform can be done in several ways such as net pan culture and caging (Figure 2). Scott and Muir (2000) provides an overview of the offshore cage systems which are currently available (Figure 3). The advantages of fish farming on offshore platform are that; high volume of good water quality throughout the fish life, easy management and increased of local employment (Kolian and Sammarco, 2005).

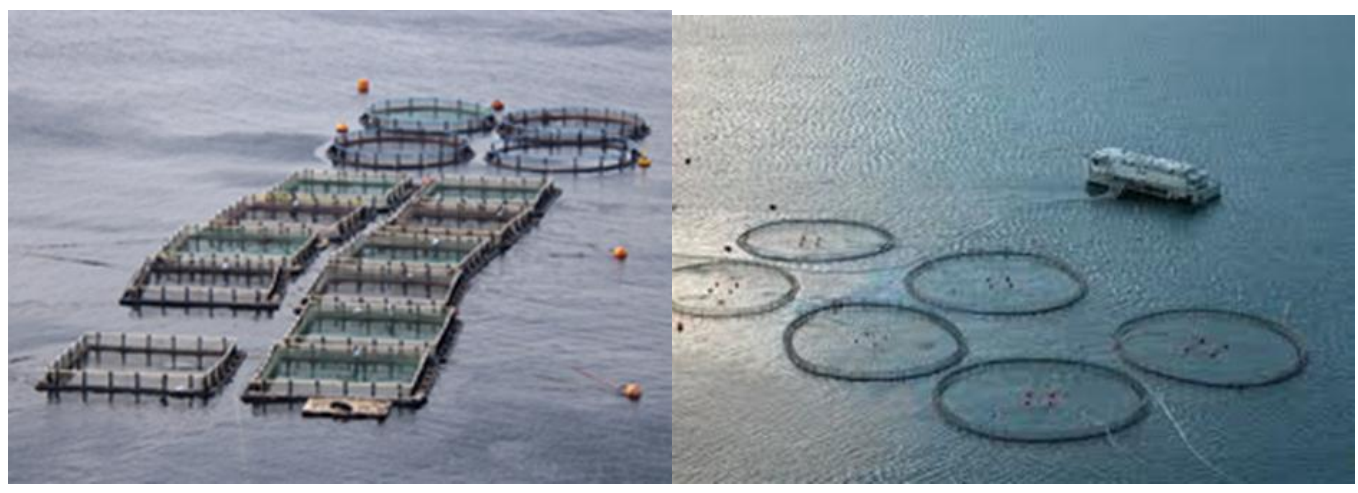

Fig 2: Open-typed fish pan.

For the biological reason, offshore mariculture on platforms also will ensure clean and unpolluted oceanic water. The growth rate of the marine species will also be rapid as the constant year-round temperature and salinity. There are also capability of raising high-value marine species and greater harvest density due to higher dissolved oxygen rates. Financially, there are no pumping or aeration costs to be worried. Besides, there are also existing infrastructure from the oil industry such as boas, cranes, and workforce. Hence, there is not much to be invested in this area.

For offshore fish farming, the platform serves as operational hub for the necessary activities where all facilities related to farm fishing and crew are provided. It easily supports quarters for crew, storage for food and other supply, docking facility and monitoring spot. All the structure for listed facilities is available from the previous operation of oil and gas exploration. Besides reusing part of the structure for operational hub, the structure of platform can be used and manipulated as an anchor for mooring type the cage and net nearby and off the platform. The structure of the platform also can be used as the spot for hatchery operation reduces the needs for transportation and operational cost (Goldburg and Naylor, 2005).

(a)

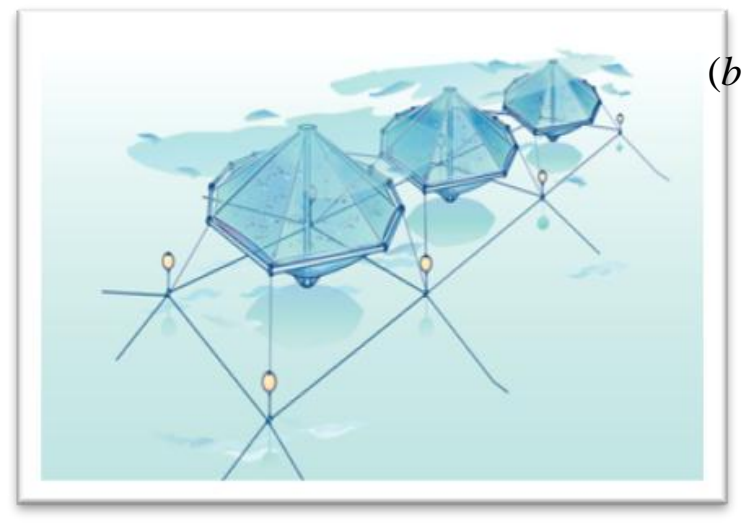

(b)

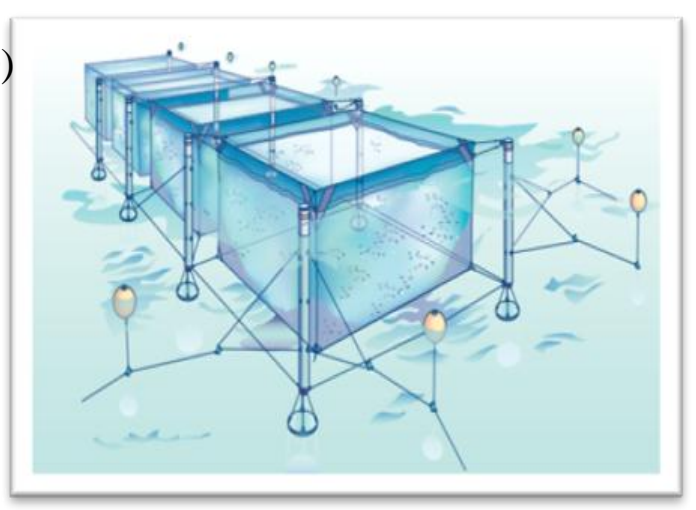




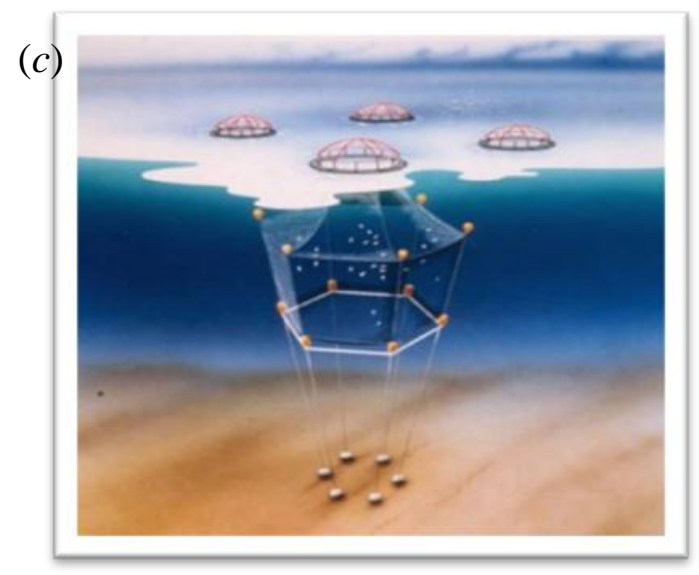

Fig 3: Several others cages and pans suitable for offshore fish farming such as; (a) sea station (b) aqua spar (c) suspension tank (Scott and Muir, 2000).

Seawater surrounding the offshore platform or water at $3 \mathrm{~km}$ distances from shore has low nutrition value and this characteristic is beneficial for fish farming as it reduced the potential algae and phytoplankton bloom as well as other dangerous bacterium. This is beneficial especially in protecting the seawater and marine creatures from pollution and disease caused by the bacterium (Kolian and Sammarco, 2005). Besides that, condition of seawater at most offshore platform will promote less pollution due to slow rate of sedimentation of pellet compare with shore farming.

As a general, fish farming activities do not require high amount of energy which means the energy required to operate the farming can easily be generated by using renewable energy applications such as wind, solar, wave and vortex-induced sea current. Since the farm will be located offshore in deep waters it is required that the farm to be operated with minimal human interaction and be able to internally generate required amount of energy to support its operation for a considerable period of time.

At most of the offshore platforms wind is available in a very high density plus most of the wind turbine structure can be supported by the platform itself so the problem of high cost for building the wind generator structure can be reduced. For solar energy, the solar panel can be placed anywhere on the platform as the sunlight intensity is high especially in the location of on the ocean. Besides that, the solar panel can provide shading from the sunlight. This shading might be required for baby fish or for some other fish activities such breeding. Wave and vortex-induced energy can be generated using sea current and tidal (Bernitsas et al., 2008). Continuous ocean current available surrounding the platform can be utilized to generate sustainable energy.

\section{Design of Offshore Mariculture Farm}

Basically, any offshore platform can be transformed to a fish farming plant with any types of fishes. The location of the platform, water depth, water temperature and surrounding condition will determine the suitable type of fish and also the design. For a deep water platform, usually the farming scale can be range from medium to big scale farming with numbers of nets and wider area of farming. There are several options of fish farming plant ideas that will be discussed. The design will include some other simple marine culture such as oyster depuration and seaweed planting.

For the first design idea, only single aquaculture activity or only single type of fish is focused and farmed on a single platform in an enclosed cage (Figure 4). Basically this is due to the location of the platform that determines distance from offshore, depth, temperature and visibility of water. Certain fish type is safer and healthier to be farmed in certain depth and temperature.

Oyster and mussel are likely suitable to be farmed at a location with water depth of more than 50 feet (Figure 5) and other creatures will have the same issues with water temperature and depth. Ornamental fish only 
suitable in the clear and good visibility water to accelerate the growth of coral reef which is the 'home' for ornamental fish.

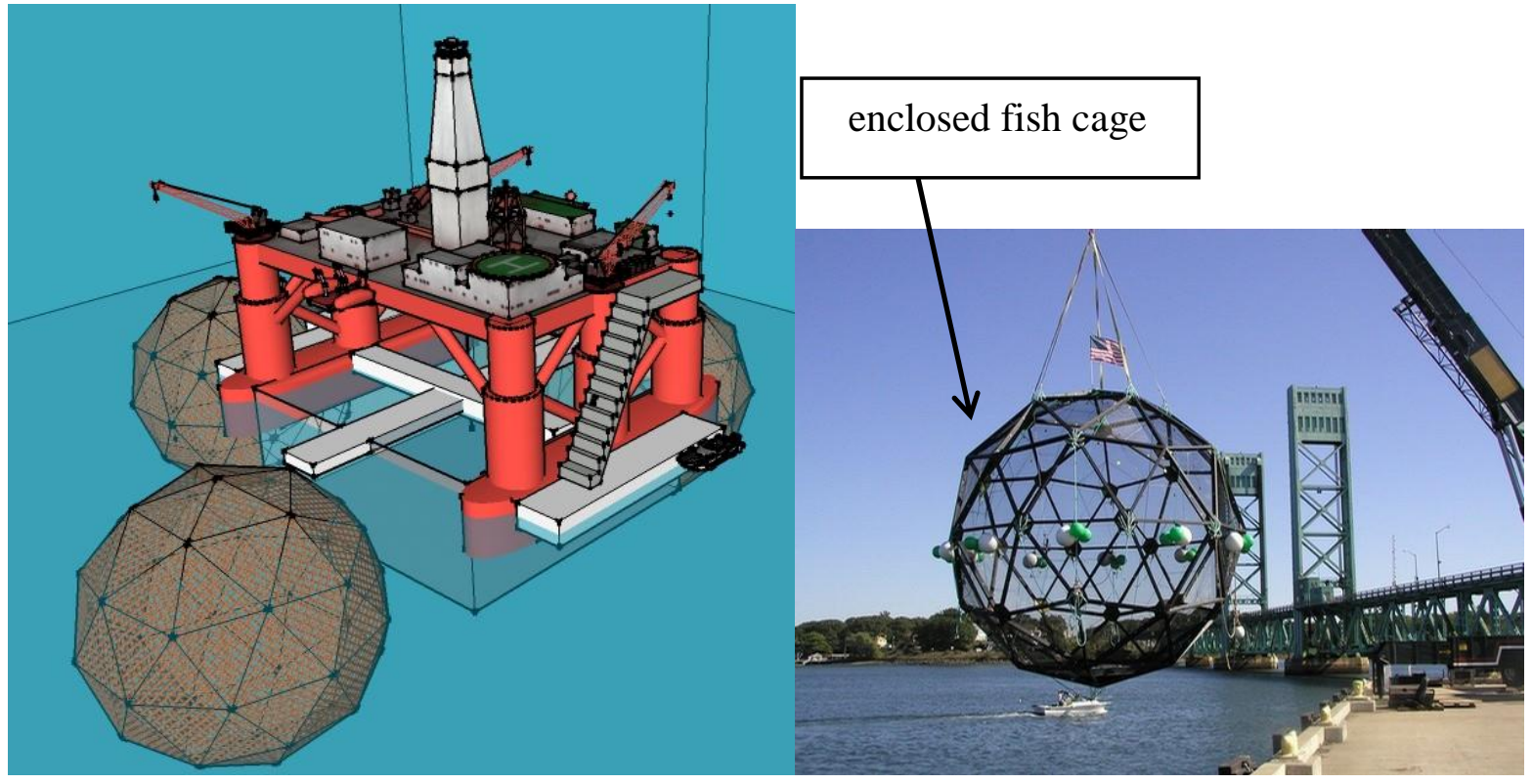

Fig 4: Simple design of fish farming on offshore platform with enclosed cage (Kirkham, 2009).

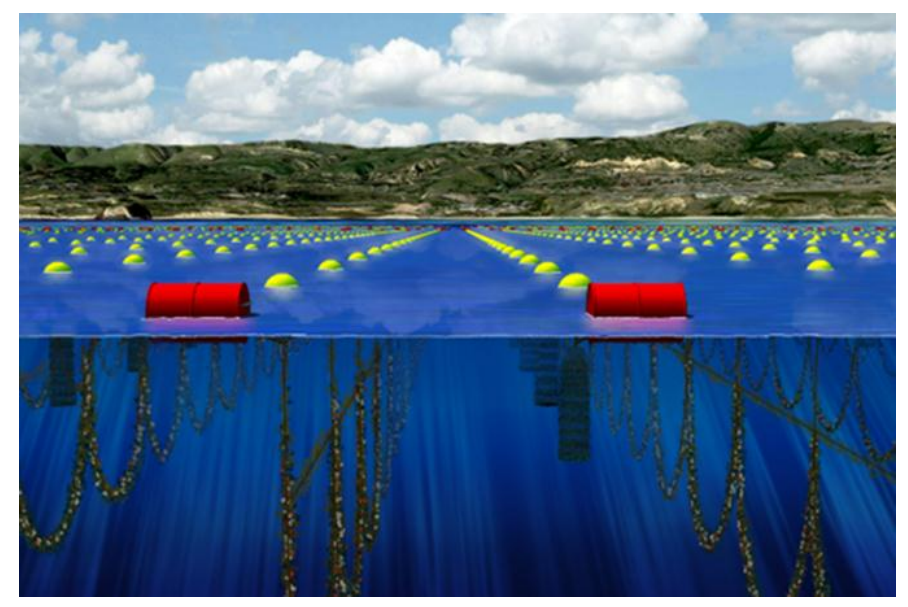

Fig 5: Shellfish aquaculture (Cruver, 2011).

Basically, the present secondary structure of platform such as office, control room and living hostel can be renovated and transformed to operational hub station such as hatch tank for young creatures to growth before ready to be transferred to the cage in the seawater. The platform also can be used as the development facilities specifically for the creatures farmed. Laboratory, research center, product processing center and food storage can also be built from the present offshore structure. In other words, it is a one stop center and the only limitation is the transportation to the shore. All other existing machineries and structure such as cranes, living compartment can supplement the farming activities.

In the design, all electrical power required for the operation is supported by the renewable wind energy generator and other sources as stated before. For a small farming activities and small platform, single wind turbine is sufficient to support all the energy needs. The pillars of the platform can be used as the foundation and anchor for the wind turbine structure and thus there is no requirement for additional major structure addition (Figure 6). 


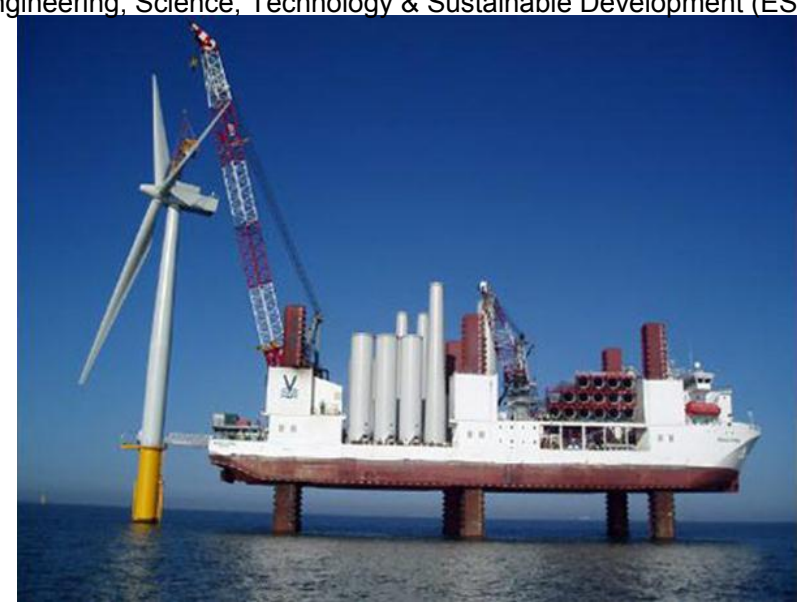

Fig 6: Wind farm off the coast of Cape Cod.

For the second farming idea, multiple aquaculture activities with multiple types of fishes can be integrated into a single platform operation; fish farming, oyster, mussel and seaweed depuration. Basically, these integrated activities require larger area of farming system to prevent inter-diseased spreading between each farmed species especially from oyster and mussel to the farmed fish. Basically, the design is quiet similar to the previous design. The only different is that this option involves larger fish caging area and more complicated managing system as well as more facilities to support the activities. The level of energy requires integrated systems of renewable energy technologies for sustainable operations (Figure 7).

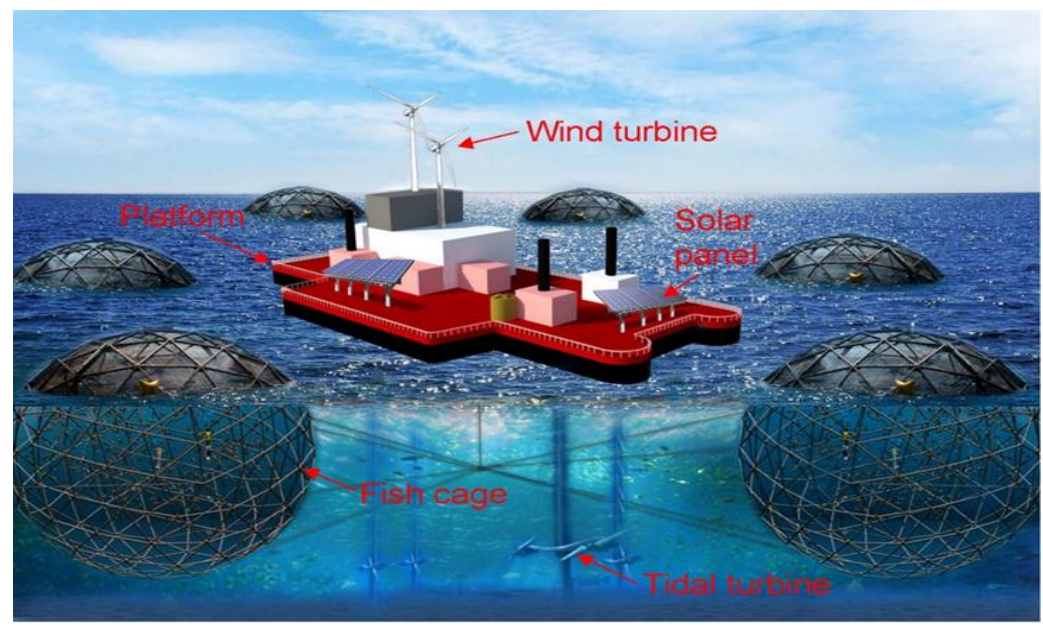

Fig 7: Integrated systems of renewable energy technologies for large offshore mariculture operations on decommissioned oil and gas platform.

For oyster and mussel farming, deeper water and lower water temperature environment are required to produce high quality oyster. Because of the reason, oyster and mussel will be farmed in the water portion under the platform for extra shading from sunlight and thus lower water temperature. By this way, the creatures can be submerged in a less water depth as the shading provided will lower the temperature of water particularly under the platform.

Seaweed requires certain amount of sunlight as the perfect environment to growth but excessive and direct sunlight will reduce the growth rate of the creatures. Thus, certain level of shading is required and can be provided by using net shading that can be planted on both of the platform and in the water. If the platform has a very large area, the seaweed can be farmed on the platform in the tank with continuous circulated sea water by pumps.

The existence operational structure can be recycled and modified to suit the aquaculture activity and research development. Laboratory, food storage, living compartment, office and process center can be developed 
using the existing platform structures. For power generation, similar wind turbine generator, solar, vortex induced and wave as in the previous option can be utilized.

For the third option, more than one platform (e.g. remote platform) that is located close to each other integrates to produce large fish farming center (e.g. mother platform). Every single platform will only conduct and focused on single type of fish. For the power generation, every platform will harness their own renewable energy for cost wise as well as safety reason. If the energy is generated only in a particular platform and shared with the other platform, there are issues of cable connection that is costly and unsecured for vessel to pass through it. If the location of the platform is close enough to each other, the living compartment or operator living compartment can be made in one single platform and the other platform can be utilized fully for the aquaculture activity such as tank farming and research center.

\section{Conclusion}

As a conclusion, there are many designs of fish farming system that can be integrated with the oil and gas offshore platform. Besides meeting the protein demand for coming years, reusing the platform for such purpose will beneficial in terms of cost and money for both the farming owner as well as the platform owner. Reusing the platform for aquaculture will definitely save the habitat and coral on the submerged platform structure besides deleting the needs of decommissioning the platform that is costly. In the coming years, multiple mode of aquaculture activities will be available and feasible to be conducted on the platform and better technology will be offered. The next step of the work would be to conduct feasibility and field studies on the renewable energy technologies to be applied on the platform.

\section{References}

[1] Kurian V. and Ganapathy C., "Decommissioning of Offshore Platforms". Proceedings of 2nd Construction Industry Research Achievement Int. Conf., Kuala Lumpur, Malaysia, 2009.

[2] O'Connor P.E., "Case Studies of Platform Reuse in the Gulf of Mexico", Int. Conf. on Reuse of Offshore Production Facilities, Netherlands, 1999.

[3] Sarah S., "The Blue Food Revolution". Scientific American, pp. 55-61, 2011

[4] Scott, D.C.B. and Muir J.F., "Offshore Cage Systems: A Practical Overview". CIHEAM - Options Mediterraneennes, pp. 79-89, 2000.

[5] Kolian S., and Sammarco P.W., "Mariculture and Other Uses for Offshore Oil and Gas Platform". Technical Report, Louisiana: Eco-Rigs of Eco-Endurance Center, 2005.

[6] Goldburg R. and Naylor R., "Future Seascapes, Fishing and Fish Farming". In Ocean Farming, pp. 21-28, 2005. https://doi.org/10.1890/1540-9295(2005)003[0021:FSFAFF]2.0.CO;2

[7] Bernitsas M.M., Raghavan K., Ben-Simon Y. and Garcia E. M. H., "VIVACE (Vortex Induced Vibration Aquatic Clean Energy): A New Concept in Generation of Clean and Renewable Energy from Fluid Flow". Journal of Offshore Mechanics and Arctic Engineering, ASME Transactions, Vol. 130, No. 4, pp. 041101-15, 2008.

https://doi.org/10.1115/1.2957913

[8] Kirkham C., "Fish Farming in the Gulf; About to Happen?"

(http://lacoastpost.com/blog/?p=2009)

[9] Cruzer, P., "Sustainable Shellfish Aquaculture". Eco-business.com 2011.

(http://www.eco-business.com/opinion/sustainable-shellfish-aquaculture/) 